\title{
Application of Decision Support Systems and Its Impact on Human Resources Output: A Study of Selected Universities in Zimbabwe
}

\author{
Bongani Ngwenya* \\ Faculty of Business, Solusi University, Bulawayo, Zimbabwe \\ *Corresponding author: nbongani@gmail.com
}

Received January 07, 2013; Revised May 06, 2013; Accepted May 11, 2013

\begin{abstract}
The increased usage of computer based decision support systems is perceived as transferring decision authority to software programs. This has led to the notion that decision making power has been somewhat transferred from human decision makers and over centralized on the machine in the decision loop. The question is, has this enhanced the effectiveness of the decision support system in selected Universities in Zimbabwe? The findings of this study are that, to a great extent decision support systems are effective in assisting decision making in organisations. Responses from management were concentrated on the higher positive side showing that they agreed that most of the human resource elements were improved by use of the decision support systems. It was recognized that the older the respondent the quicker they solve problems and accurate data collection was found to increase the decision scope.
\end{abstract}

\section{Keywords: decision support system; decision making; decision scope; decision loop; decision authority}

\section{Introduction}

Making decisions concerning complex systems, such as management of organisational operations, industrial processes, investment portfolios, the command and control of military units, or the control of nuclear power plants often strains our cognitive capabilities [13]. Even though individual interactions among system`s variables may be well understood, predicting how the system will react to an external manipulation such as a policy decision is often difficulty [5]. In many situations the quality of decisions is important, aiding the deficiencies of human judgment and decision making has been a major focus of science throughout history [6]. More recently, these methods, often enhanced by a variety of techniques originating from information science, cognitive psychology, and artificial intelligence, have been implemented in the form of computer programs, either as stand-alone tools or as integrated computing environments for complex decision making. Such environments are often given the common name of decision support systems (DSSs) [5].

It is suggested in literature that billions of business transactions are recorded in enterprise scale data warehouses every day hence information by itself is no longer perceived as an asset, its acquisition, storage and management are commonplace and often automated [9]. A systematic review of the literature during the period 19902007 in the realm of initiating therapy found some indication of greater effectiveness of Clinical Decision Support Systems (CDSSs) after, rather than before, drug selection. Also a critical appraisal of research on Clinical
Decision Support Systems [17] concluded that strong evidence suggests that some decision support systems can improve physician performance. Additional well-designed studies are needed to assess their effects and costeffectiveness, especially on patient outcomes [10].

A study and publication on Management Science carried out in America found that the research subjects who used DSSs made significantly more effective decisions than the subjects that did not have access to DSSs [30]. While there is substantial empirical evidence on the improvements that information system have in supporting the decision making loop other scholars suggest that the human element is being overridden in the process, thus transferring decision making power to the computer [25]. Building DSSs, especially knowledgedriven DSSs, may be perceived as transferring decision authority to a software program [24]. The researcher goes further to suggest that they advocate building computerized decision support systems because they want to see an improvement of decision making while keeping a human decision maker in the 'decision loop'. Proper application of decision-making tools are said to increase productivity, efficiency, and effectiveness and gives many businesses a competitive advantage over their competitors, allowing them to make optimal choices for technological processes and their parameters, planning business operations, logistics, or investments [5]). It is with this notion that the researcher sought to evaluate the effectiveness of the decision support systems in both state and private Universities, in terms of the human resource efficiency that should be an outcome of their usage.

In the order of consideration, the author first examines some insights from the literature and conceptual framework. Following the examination of the literature 
and the discussion of the conceptual framework, the researcher develops a hypothesis that is tested using the Statistical Package of Social Sciences (SPSS).The research methodology is outlined, followed by the analysis of the data, and discussion. Finally, the conclusions are drawn and recommendations for further future research are made.

\section{Insights from the Literature and Conceptual Framework}

The section that follows presents the literature upon which the conceptual framework of the study is based. The review of the related scholarly views focuses on the structure of decisions and the benefits derived from the DSSs. Important themes are derived from literature and form the basis of the conceptual framework. See Figure 1, below.

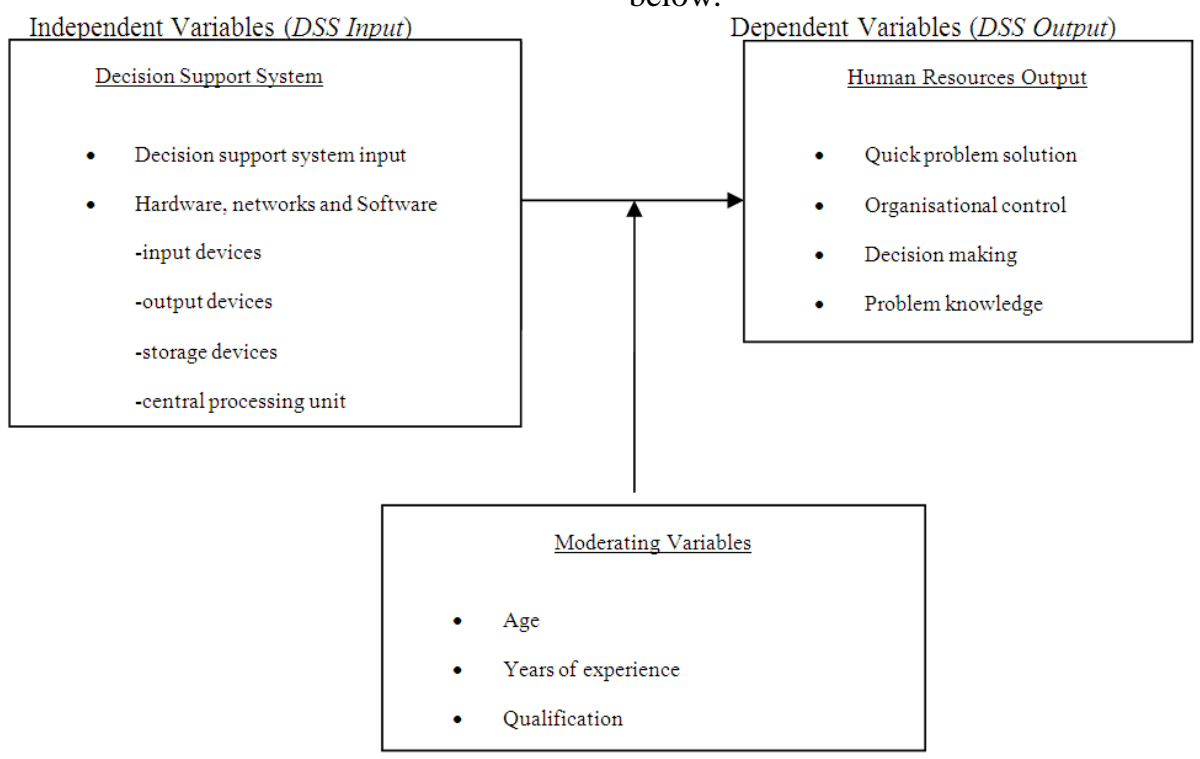

Figure 1. Conceptual Framework

\section{Hypothesis}

From the above conceptual framework the researcher draws a single null hypothesis:

Ho: Human resource output is not significantly related to Decision Support Systems and the moderating variables (age, years of experience and qualification)

The section that follows deals with the Independent variable: Decision Support System (DSS input) and its sub-variables, hardware, networks and software; data collection; analysis and reporting tools; learning and training.

\subsection{Decision Support System}

A Decision support system is a computer-based system that enables management to interrogate the computer system on an ad hoc basis for various kinds of information in the organisation and to predict the effect of potential decisions beforehand. Drawing on various definitions that have been suggested [1,20,32] a DSS system can be described as a computer-based interactive human computer decision-making system that:

- Supports decision makers rather than replace them

- Utilizes data and models

- Solves problems with varying degrees of structure

a) non-structured (unstructured or ill-structured)

b) semi-structured

c) semi-structured and unstructured

- Focuses on effectiveness rather than efficiency in decision processes (facilitating decision processes).

DSS support technological and managerial decision making by assisting in the organisation of knowledge about ill-structured, semi-structured, or unstructured issues. A structured issue has a framework comprising elements and relations between them are known and understood [3]. Emphasis in the use of a decision support system is upon provision of support to decision makers in terms of increasing the effectiveness of the decisionmaking effort [8]. This support involves the systems engineering steps of formulation of alternatives, the analysis of their impacts, and interpretation and selection of appropriate options for implementations [7].

\subsubsection{Classification of Decision Support Systems}

Decision Support Systems applications are classified in several various ways. Some researchers have classified DSS into the following six frameworks: Text-oriented DSS, Database-oriented DSS, Spreadsheet-oriented DSS, Solver-oriented DSS, Rule-oriented DSS, and Compound DSS [16]. A compound DSS is the most popular classification for a DSS. It is a hybrid system that includes two or more of the five basic structures described by Holsapple and Whinston. Furthermore the support given by DSS can be separated into three distinct, interrelated categories: Personal Support, Group Support, and Organisational Support.

\subsubsection{Decision Support System Input}

As part of the functional inputs, a DSS is run and supported by good hardware, software requirements, a good network and operating system. Literature differs on which technologies to use depending on when the literature was written and what technologies in this area were present then. It is therefore a general consensus among scholars that the best hardware, software networks 
and operating systems that form the basis of every DSS will therefore depend on compatibility and what is latest technology for maximum output and utilization; technology is evolving, it is not stationary [16].

\subsubsection{Hardware, Networks, and Software}

A decision support system is not a single piece of technology, such as a database, file server, or network. Rather, it is a system for incorporating and integrating disparate data sources to better allow decision makers to access and compile data in a useful format [31]. In general, most decision support systems will include the hardware, networking technologies, and operating systems necessary for supplying and supporting databases and/or servers; a user interface with mechanisms for accessing, manipulating, and transferring data; and some type of repository for temporarily or permanently storing data. Key technical requirements often revolve around issues such as accessibility, processing and transfer speed, scalability, interoperability, cost effectiveness, and security [35].

\subsubsection{Hardware}

Hardware comprises of the physical devices that make up a computer (often referred to as a computer) such as the keyboard, mouse and monitor. All hardware falls into one of the six categories namely:

Input devices: tools used to capture information and commands.

Output devices: tools used to see, hear, or otherwise accept the results of the information processing requests.

Storage devices: tools used to store information for use at a later time.

Central processing unit (CPU): the actual hardware that interprets and executes the software instructions and coordinates how all other hardware devices work together.

Telecommunications devices: tools used to send information to and receive it from another person or location. It basically describes our ability to be connected to almost anyone, anywhere and at any time. Telecommunications enables the concept of a network.

Connecting devices: include such things as parallel ports into which a printer and connector cords are connected.

Computer hardware provides the platform on which the operating system runs which in turn houses the decision support system. It is also the interface with which users interact with in carrying out their daily work. A decision pport system is therefore accessible via the hardware [35].

\subsubsection{Networks}

A network is a group of computers and other devices (such as printers) that are connected by some type of transmission media. They communicate through copper wires, fibre-optic cable, radio waves, infrared, or satellite links [15]. Most importantly, networks enable multiple users to share devices such as printers and data such as spreadsheet files, which are collectively known as the network's resources [21]. Sharing devices also saves time, than sneaker net [38]. It is not surprising, then, that most businesses depend on their networks to stay competitive [11].
An operating system (OS) is a software program that enables the computer hardware to communicate and operate with the computer software. An OS is an interface between hardware and user which is responsible for the management and coordination of activities and the sharing of the resources of a computer that acts as a host for computing applications run on the machine [33]. Operating systems offer a number of services to application programs and users. Applications access these services through application programming interfaces (APIs) or systems calls. Users may also interact with the operating system with some kind of software user interface like typing commands by using command line interface (CLI) or using a graphical user interface. Whether the user interface should be included as part of the operating system is a point of contention [35].

\subsubsection{Data Collection}

Data collection forms the foundation on which the decision system makes or derives its source of decision making [36]. It is therefore essential on how data is captured at entry point; the expertise of those involved should be such that any data collection exercise requires advance planning, recruitment and training of staff [27]. Once data has been captured it follows therefore that it has to be stored in a database of some sort. A Data warehouse is a repository of an Organisation's electronically stored data. A data warehouse houses a standardized, consistent, clean and integrated form of data sourced from various operational systems such as DSS in use in the organisation. A data warehouse and data aggregators are major components of the DSS. They assist in the storage and analytical process [36].

\subsubsection{Quality of Data}

Making the right decision in business is usually based on the quality of the data collected. Errors in data collection are a source of risk since information systems are no better than the data they contain, the assumption being that the system will operate reliably and that the information generated will be correct. However when these assumptions are proved wrong, the consequences can be disastrous [34]. Poor data quality may stem from errors during data input or faulty information systems and database design [21].

\subsubsection{Analysis and Reporting Tools}

Analysis tools: An analysis tool is basically an instrument that applies business rules or other logic to data in order to derive meaning. This includes time series analysis, cost allocations, data mining, and other userdriven manipulation and investigation. Analysis tools are available in many software applications, including spreadsheets, databases, and other stand-alone programs [22]. In a DSS environment, however, analysis tools are particularly powerful because they rely on On-Line Analytical Processing (OLAP) technologies. OLAP tools are applications that permit users to browse, query, analyze, and summarize large amounts of data in an efficient, interactive, and dynamic way [2]. The ability to manipulate data in multiple dimensions improves data analysis and reporting capabilities, making OLAP cubes

\subsubsection{Software, or Operating System}


invaluable for data mining, data management, and trend analysis and powerful analytical components of DSSs [2].

Reporting tools: Robust reporting tools are a major element of any DSS. Presenting information in multiple formats (as a blend of text, tables, and graphics) and in multiple dimensions, changing an axis to present information more clearly, sometimes further clarifies the meaning of the data. Unlike a date warehouse or database, which both focuses on data storage, a DSS often includes reporting tools that permit a user too easily:

- Place headings, titles, and explanatory information within charts, tables, and other derived figures;

- Add borders and shading to clarify and highlight important information and groupings;

- Modify font size and style to emphasise points;

- Move, edit, or delete data, text, and graphics in final reports;

- Produce a wide range of figures, including bar graphs, pie charts, bar and line graph combinations, multiple axis graphics, and scatter plots;

- Export data in various formats (such as, ASCII, Excel);

- Generate reports in various formats (such as, html, PDF, e-mail, paper); and

- Include legends, citations, explanations, and other information.

A DSS`s reporting functions must serve a wide range of users including novices and users with expert analytical capabilities. To accommodate this, most systems offer two primary classes of reporting tools: (1) predefined (static) reports that require little system expertise and are ideal for users with typical information needs; and (2) dynamic (adhoc) report-generating capabilities that require greater understanding of both the data and the querying technology, but allow users to investigate more complex questions [2].

Predefined reports: Some types of data requests are quite common: How many clients are on savings accounts this year? How many students graduated last year? What percentage of clients took loans in the past five years? Because these and many other data requests are quite common, they can be anticipated and are often preprogrammed, in predefined reports.

Ad-hoc reports: Whenever existing, predefined reports cannot provide an appropriate response to a query, users may be able to customize their request and generate an adhoc report. In the context of querying, ad-hoc refers to a data request that is tailored to meet the specific needs of an individual user. Clearly, users who require ad-hoc reporting tools will probably need a more sophisticated understanding of how to use querying tools [2].

\subsubsection{Learning and Training}

The concept of DSSs and its evolution over the last decade provides a useful model to think about many management issues associated with end user computing. Since the DSS user may also adopt the role of the builder, there is a direct analogy between the concept of DSS and that of end user [28]. Embedded in this design concept is a strong view of the user as a learner. Traditional benefits of DSSs are often linked to improved understanding and task learning. The "what if" capability, perhaps coupled with a powerful normative model can aid the decision maker [14] in reaching a "better" (ideally optimal) decision. Learning can occur as a by-product of initial and ongoing use of a DSS. Two types of learning seem to occur: learning of new concepts and the development of a better factual understanding of the business and decision making environment. Some DSSs serve as "de facto" training tools for new employees.

\subsubsection{User Training}

Properly trained users are perhaps the most critical component of effective DSSs. After all, people, not DSSs, make decisions the DSS is only the tool that supports a decision making process undertaken by users. In fact, the most difficult aspect of using a DSS is not implementing the technology, but knowing what questions to ask, how to ask them, and how to interpret the answers, that is, how to read the reports. Fortunately, users can be trained to understand the data and its limitations, as well as the system and its capabilities. The best way to ensure that users know how to use the system and data appropriately is to train them [2].

The section that follows deals with the Dependent variable: Human Resource Output (DSS output) and its sub-variables, quick problem solution; organisational control; decision making; problem knowledge; interpersonal communication; decision scope.

\subsection{Human Resource Output}

There is a deeply-seated and pervasive notion among scholars that decision making in commercial settings is an individual activity: that isolated managers or analysts, often using personal computers, make business decisions. Similarly it is [4] noted that most businessmen still believe that decisions are made by top management. But the business enterprise of today is no longer an organisation in which there are a handful of bosses at the top who make all the decisions while the workers carry out orders. It is with this notion that this paper sought to review literature on several human resources issues that relate to DSS as an assessment of its effectiveness in the business environment.

\subsubsection{Quick Problem Solution}

Every decision involves a certain amount of risk [12]. When too much information is sought and obtained, one or more of several problems can arise [29]. (1) A delay in the decision occurs because of the time required to obtain and process the extra information. This delay could impair the effectiveness of the decision or solution. (2) Information overload will occur. A major problem caused by information overload is forgetfulness. (3) Selective use of the information will occur. That is, the decision maker will choose from all the information available only those facts which support a preconceived solution or position. (4) Mental fatigue occurs, which results in slower work or poor quality work. (5) Decision fatigue occurs, where the decision maker tire of making decisions. Often the result is fast, careless decisions or even decision paralysis-no decisions are made at all. The time savings that have been documented from using computerised decision support are often substantial [29].

\subsubsection{Effective Organisational Control}


Increasingly, computers are being used to collect and store information for control purposes. Many organisations privately monitor each employee's computer usage to measure employee performance, among other things. Organisational control includes any process designed to assure that organisation plans are carried out the way they were designed. To increase organisational control Data-driven DSSs often make business transaction data available for performance monitoring and ad hoc querying. Such systems can enhance management understanding of business operations and managers perceive that this is useful [29]. Accordingly [29] effective control systems share several common characteristics; these are common in DSSs. These characteristics are as follows:

- A focus on critical points. For example, controls are applied where failure cannot be tolerated or where costs cannot exceed a certain amount. The critical points include all the areas of an organisation's operations that directly affect the success of its key operations.

- Integration into established processes. Controls must function harmoniously within these processes and should not bottleneck operations.

- Availability of information when needed. Deadlines, time needed to complete the project, costs associated with the project, and priority needs are apparent in these criteria. Costs are frequently attributed to time shortcomings or failures.

- Economic feasibility. Effective control systems answer questions such as, "How much does it cost?" "What will it save?" or "What are the returns on the investment?" In short, comparison of the costs to the benefits ensures that the benefits of controls outweigh the costs.

- Accuracy. Effective control systems provide factual information that's useful, reliable, valid, and consistent.

\subsubsection{Decision Making}

DSSs are a form of computer-based information systems (IS) that support individual decision makers in the decision-making process, with the goal of improving decision quality in recurring, low-structure tasks requiring human judgment [18]. There are several examples of DSSs use in the decision making process. One such example is Real Plan, which is a DSS package for the commercial real estate industry. Real Plan analyses lease and rental terms, including cost-of-living adjustments, and makes forecasts for the future [23]. Accordingly [37] the success of a decision is a function of its quality and of how it is implemented. Decision quality is judged by a decision`s compatibility with existing constraints, its timeliness, and its incorporation of the optimal amount of information. Literature [19] presents the following explanations of these important concepts. They suggest that effectiveness in decision-making requires addressing the process of identifying what should be done, efficiency in decision-making addresses the means for performing a given defined task in order to achieve outputs as well as possible, relative to some predefined performance criteria.

\subsubsection{Interpersonal Communication}

DSSs can improve communication and collaboration among decision makers. In appropriate circumstance, communication-driven and group DSSs have had this impact. Model-driven DSSs provide a means for sharing facts and assumptions. Data-driven DSSs make "one version of the truth" about company operations available to managers and hence can encourage fact-based decision making. Improved data accessibility is often a major motivation for building a data-driven DSS. This advantage has not been adequately demonstrated for most types of DSSs [19]. The researcher goes further to suggest that people engage in interpersonal communication because they need to express and receive interpersonal needs and because of the different roles users play on the system and the dependability of one's work on that of another it is inevitable that communication between the users will always improve mainly progress driven.

\subsubsection{Enhanced Decision Scope}

Every decision is made within a decision environment, which is defined as the collection of information, alternatives, values, and preferences available at the time of the decision. An ideal decision environment or decision scope would include all possible information, all of it accurate, and every possible alternative. The time constraint simply means that a decision must be made by a certain time. It's like spending three hours and half tank of gas trying to find the very best parking place at the mall [12]. Since decisions must be made within this constrained environment, we can say that the major challenge of decision making is uncertainty, and a major goal of DSSs and decision analysis is to reduce uncertainty and enhance the decision scope.

\subsubsection{Enhanced Problem Knowledge}

There is an ever present drive to make the decisions objective. Subjectivity is associated with incorrect, illconceived and poor decisions. However, some researchers [7] argue that the managers are hired to make the subjective decisions. The managers are routinely called upon to sift the data available, that is, data not necessarily collected to support the decision question at hand to take decisions based on their personal judgment and biases. Ability to make these subjective decisions distinguishes a good manager from a novice. Computer databases have been in routine and common use for a few decades now. Organisations, all over the world, have accumulated data perceived to be relevant to their interests [26]. In the process new approaches of thinking about a problem space are revealed. Knowledge driven DSSs can suggest or recommend actions to managers. These expertise consist of knowledge about a particular domain, understanding of problems within that domain, and skill at solving some of these problems. A related concept is Data Mining. It refers to a class of analytical applications that search for hidden patterns in a database. They increase the decision makers problem space in coming up with solutions [5].

\section{Research Methodology}

Questionnaires were distributed to 43 people in management positions in the Information Technology (IT) departments of the 13 Universities in Zimbabwe. The research used a quantitative descriptive method to assess the effectiveness of DSSs, being study of Universities in Zimbabwe. The study focused on finding the relationship between DSSs and human resource output and how they 
are affected by the moderating variables as depicted by the conceptual framework. The samples used for the questionnaire were picked and chosen according to their age, years of experience and qualification in order to guarantee that they had the necessary computer skills to use and they applied DSSs in their operations and decision making processes. Evaluation and scoring of responses on the questionnaire is as shown in Figure 2 below.

\begin{tabular}{|l|l|l|l|}
\hline Scale & Responses & Verbal Interpretation & Scaled Interval \\
\hline 5 & SA $=$ Strongly Agree & Usual practice & $4.51-5.00$ \\
\hline 4 & $\mathrm{~A}=$ Agree & Frequently but not usual practice & $3.51-4.50$ \\
\hline 3 & UD $=$ Undecided & Not sure & $2.51-3.50$ \\
\hline 2 & $\mathrm{D}=$ Disagree & Infrequent, or rarely the practice & $1.51-2.50$ \\
\hline 1 & SD $=$ Strongly Disagree & Not implemented at all & $1.00-1.50$ \\
\hline
\end{tabular}

Figure 2. Evaluation and scoring of questionnaire

\section{Analysis of Data}

The general information on the demographic characteristics of the population was gathered from personnel in management positions in the IT departments of the Universities that use DSSs in their operations. Table 1 below summarizes the distribution of respondents according to qualification.

Table 1. Distribution of respondents according to Qualification

\begin{tabular}{|c|c|c|c|c|}
\hline & Frequency & Percentage & $\begin{array}{c}\text { Valid } \\
\text { Percentage }\end{array}$ & $\begin{array}{c}\text { Cumulative } \\
\text { Percentage }\end{array}$ \\
\hline Valid O Level & 1 & 2.3 & 2.3 & 2.3 \\
\hline A Level & 3 & 7.0 & 7.0 & 9.3 \\
\hline $\begin{array}{c}\text { Higher Certificate } \\
\text { /Diploma/HND }\end{array}$ & 14 & 32.6 & 32.6 & 41.9 \\
\hline Degree & 18 & 41.9 & 41.9 & 83.7 \\
\hline Masters/PhD & 7 & 16.3 & 16.3 & 100.0 \\
\hline Total & 43 & 100.0 & 100.0 & \\
\hline
\end{tabular}

A total of $90.8 \%$ of the respondents meets the basic minimum qualification of Higher Certificate/Diploma to Masters/PhD levels. Because of this level of literacy, the researcher safely concluded that the respondents responded genuinely and without influence from other people as they did not necessarily have to look for an interpreter or reader. Their literacy level also means that they fully comprehended the instrument and answered knowledgably. Table 2 below summarizes the distribution of respondents according to age.

As part of the demographic data, information obtained about the ages of the respondents was distributed in such manner that $27.9 \%$ of the respondents were aged between 31 and 35 years of age, while $25.7 \%$ of the respondents were between 26 and 30 years of age. Only $11.6 \%$ were above 41 years of age which could be explained by that most of the respondents were in lower and middle management, higher level management were generally older and constituted a small portion of the respondents that is $11.6 \%$ for those forty one and above. The Table 3 summarizes the distribution of respondents according to years of experience.

The majority of the respondents were experienced as the results show that at least $80.6 \%$ had worked for at least 3 years and they should have understood better how the DSSs operate. Management positions in Zimbabwean Universities have a minimum requirement of between 3 to 5 years work experience. This therefore means that at least $80.6 \%$ of the respondents are well experienced for their jobs therefore give an opinion reflecting on what actually obtains in their organisations. This meant that their responses were more accurate and a true representation of what actually takes place in their organisations. Table 4 below summarizes the opinion of respondents in regards to the effectiveness of DSSs.

Table 2. Distribution of respondents according to age
\begin{tabular}{|c|c|c|c|c|}
\hline Age & Frequency & Percentage & $\begin{array}{c}\text { Valid } \\
\text { Percentage }\end{array}$ & $\begin{array}{c}\text { Cumulative } \\
\text { Percentage }\end{array}$ \\
\hline $21-25$ & 5 & 11.6 & 11.6 & 11.6 \\
\hline $26-30$ & 11 & 25.7 & 25.7 & 37.2 \\
\hline $31-35$ & 12 & 27.9 & 27.9 & 65.1 \\
\hline $36-40$ & 9 & 21 & 21 & 86.0 \\
\hline $41-50$ & 5 & 9.3 & 9.3 & 97.7 \\
\hline $\begin{array}{c}56 \text { and } \\
\text { above }\end{array}$ & 1 & 2.3 & 2.3 & 100.0 \\
\hline
\end{tabular}

Table 3. Distribution of respondents according to years of experience

\begin{tabular}{|c|c|c|c|c|}
\hline Years & Frequency & Percentage & $\begin{array}{c}\text { Valid } \\
\text { Percentage }\end{array}$ & $\begin{array}{c}\text { Cumulative } \\
\text { Percentage }\end{array}$ \\
\hline $1-2$ & 7 & 16.3 & 19.4 & 19.4 \\
\hline $3-5$ & 17 & 39.5 & 47.3 & 66.7 \\
\hline $6-10$ & 8 & 18.7 & 22.3 & 89.0 \\
\hline $11-15$ & 3 & 7 & 8.4 & 97.2 \\
\hline $\begin{array}{c}16 \text { and } \\
\text { above }\end{array}$ & 1 & 2.3 & 2.8 & 100.0 \\
\hline Total & 36 & 83.7 & 100.0 & \\
\hline Missing & 7 & 16.3 & & \\
\hline $\begin{array}{c}\text { Grand } \\
\text { Total }\end{array}$ & 43 & 100.0 & & \\
\hline
\end{tabular}

Table 4. Respondents opinion on effectiveness of DSSs

\begin{tabular}{|c|c|c|c|}
\hline & Dependent Variable & & Statistic \\
\hline & & Mean & Std. Deviation \\
\hline 1 & Organisational Control & 3.6476 & 0.82380 \\
\hline 2 & Quick Problem Solution & 3.9286 & 0.46711 \\
\hline 3 & Decision Making & 3.7202 & 0.49756 \\
\hline 4 & Problem Knowledge & 3.6071 & 0.60269 \\
\hline 5 & Interpersonal Communication & 3.9286 & 0.54368 \\
\hline 6 & Decision Scope & 3.5762 & 0.37011 \\
\hline & Overall Mean & 3.7347 & 0.55082 \\
\hline
\end{tabular}

Six Critical Success Factors or indicators of human resource output were selected according to their importance and effectiveness as a measure of the effectiveness of DSSs in Universities in Zimbabwe. These factors were selected from the points of view of different authors as the output of DSSs use. As shown in the tables 4 above the means of the opinions of the respondents on the effectiveness of the DSSs on human resource output were tabulated to measure the extent to which they agreed or disagreed. A mean between 3.51-4.50 was interpreted to mean that they agreed, a mean between 4.51-5.00 was taken to mean that they strongly agreed while a mean equal or less than 3.50 meant that the DSSs are not effective. The benchmark of 3.51 was therefore used as the minimum acceptable range in order to determine the extent of the opinion of the respondents on the effectiveness of the DSSs. 
The overall question was to what degree is the human resource output affected by the DSS and moderating variables as summarized by the null hypothesis; Human resource output is not significantly related to DSS and the moderating variables (age, years of experience and qualification). The regression analysis was used to find out which variables were related to the DSS and moderating variables. Years of age, quick problem solution, and data collection and decision scope were found to have significant relationships. The following statistics summarizes the regression analysis for the effect of DSSs and moderating variables on quick problem solution (Model Summary);

a. Predictors: (Constant), Years of Age

b. $F=5.709$

c. Significant level $=0.024$

d. Beta Value of 0.024 (Coefficients)

e. Adjusted R, squared=0.144

From the statistics above, of all the DSS and moderating variables only age accounted for $14.4 \%$ of the variance in quick problem solution. The F Value of 5.709 was found to be significant at 0.05 level of significance. The positive Beta Value of 0.024 shows that the older the respondent the quicker they solve problems. The following statistics summarizes the regression analysis for the effect of DSS and moderating variables on decision scope (Summary Model);

a. Predictors: (Constant), data collection

b. $\mathrm{F}=6.632$

c. Significant level $=0.016$

d. Beta Value of 0.259 (Coefficients)

e. Adjusted R, squared $=0.167$

From the above statistics, the regression analysis for the effect of DSS and moderating variables on decision scope shows that only data collection accounted for $16.7 \%$ of the variance in decision scope. The $\mathrm{F}$ Value of 6.632 was found to be significant. The positive Beta Value of 0.259 shows that the more accurate data are collected the better is the decision scope.

\section{Conclusion and Recommendations}

To a greater extent DSSs enhance the decision making process. While other scholars suggest that the human element is overridden in the decision making process, that is the DSSs transfer decision making power in the decision loop from the human element and over centralize it on the machines as viewed by other researchers [24]. This study shows that DSSs enhance human decision making capabilities within the Universities in Zimbabwe. Recommendations for future studies are made and suggested for replication of the study in other sectors of the economy, such as the financial sector in Zimbabwe and other organisations that use DSSs on a longitudinal perspective. A grounded theory study can be conducted to develop a theory on the impact of DSSs on human resource output.

\section{References}

[1] S. Alter, Information Systems: a Management Perspective, $\left(2^{\text {nd }}\right.$ ed). The Benjamin, USA (1996).
[2] G, Bairu, National Forum on Education Statistics: Forum Guide to Decision Support Systems. A Resource for Educators.

[3] W. L, Cats-Baril, and G.P, Huber, "Decision Support Systems for Ill-Structured Problems", J. Decision Sciences. Volume 18, 350372, 1987.

[4] P.F, Drucker, Long-Range Planning in Technology, Management \& Society, Harper \& Row, New York, 1967.

[5] J.M, Druzdzel, and R.R, Flynn, Information Science. Librarianship, Ed. Drake, 2005.

[6] E. Forman, and M.A, Selly, Decision by Objectives: How to Convince Others That You Are Right, World Scientific Publishing, River Edge, NJ. 402, 2001.

[7] A, Gachet, Building Model-Driven Decision Support Systems with Dicodess, VDF, Zurich, 2004.

[8] J.K. Galbraith, The New Industrial State, Signet, New York, 1971.

[9] A. R. Ganguly, and A, Gupta, "Data mining and decision support for business and science: Encyclopaedia of Data Warehousing and Mining", J. Wang Ed. Idea Group, 2005.

[10] S.R. Gordon, and J.R. Gordon, Information Systems: A Management Approach, TX: Dryden Press, Fort Worth, 1996.

[11] J.N.D. Gupta, "Intelligent Decision-making Support System: Foundation, Applications and Challenges", Springer, London, 2006.

[12] R. Harris, Introduction to Decision Making, 2009.

[13] K.B. Hemant, D.J. Power, and S. Daewon, "Decision Support Systems", 43(4), 2007.

[14] J.C. A. Henderson, Methodology for Identifying Strategic Opportunities for DSS, Massachusetts Institute of Technology Cambridge, Massachusetts, 1985.

[15] S.L. Hiquet, Network Plus, Thompson Course Technology, PTR, 2005.

[16] C.W. Holsapple, and A.B. Whinston, Decision Support Systems: A Knowledge-Based Approach, West Publishing, St. Paul, 1996.

[17] M.E. Johnston, K.B. Langton Haynes, and A. Mathieu, Effects of computer-based clinical decision support systems on clinical performance and patient outcome: A critical appraisal of research, McMaster University, Hamilton, Ontario, Canada, 1994.

[18] G.M. A .Kasper, "Theory of Decision Support System Design for User Calibration", Information Systems Research, Volume 7(2), 215-232, 1996.

[19] P.G. Keen, and M.S. Scott-Morton, Decision Support Systems: An Organisational Perspective, Reading, Addison-Wesly, Massachusetts, 1978.

[20] P.G.W. Keen, Decision Support Systems: an organisational perspective, Reading, Mass., Addison-Wesley Pub. Co, 1978.

[21] K.C. Laudon, and J.P. Laudon, Management Information Systems: Managing the digital firm, $\left(8^{\text {th }}\right.$ ed), Prentice hall, India, 2004.

[22] N.F. Matsatsinis, and Y. Siskos, Intelligent support systems for marketing decisions, Kluwer Academic Publisher, 2002.

[23] J.A. O`brien, Introduction to Information Systems, $\left(12^{\text {th }}\right.$ ed). Tata Mcgraw Hill Publishing Company Limited, 2005.

[24] D.J. Power, "What is a DSS?" The On-Line Executive Journal for Data-Intensive Decision Support, 1(3), 1997.

[25] D.J. Power, "Web-based and model-driven decision support systems: concepts and issues", in proceedings of the American Conference on Information Systems, Long Beach, California, 2000.

[26] D.J. Power, Supporting Decision-Makers: An Expanded Framework, University of Northern Lowa, USA, 2001.

[27] D.J. Power, Decision support systems: concepts and resources for managers, Westport, Conn., Quorum Books, 2002.

[28] D.J. Power, "Can computerised decision support systems impact, eliminate, exploit, or reduce cognitive biases in decision making?" DSS News. Volume 6(20), 2005.

[29] D.J. Power, An Empirical Assessment of Computer-Assisted Decision Analysis, 2007.

[30] D.J. Power, Can DSS impact decision outcomes? 2008.

[31] R. Sharda, S.H. Barr, and J.C. McDonnell, "Decision support systems effectiveness: a review and an empirical test", Management Science, 2002.

[32] H.A. Simon, The New Science of Management Decision: The Shape of Automation for Men and Management, Harper Torch Books, New York, 1965.

[33] R.H. Sprague, and E.D. Carlton, Building effective decision support systems, Prentice-Hall, Englewood Cliffs, N.J, 1982.

[34] R.M. Stair, and G.W. Reynolds, Principles of Information Systems: a Managerial Approach ( $5^{\text {th }}$ ed), Course Technology, USA, 2001. 
[35] H. Stephen, M. Cummings, and D.J. McCubbrey, Management Information Systems for the Information Age" $\left(4^{\text {th }}\right.$ ed), McGrawHill/Irwin, New York, USA, 2004.

[36] D. Tablin, "Comparison of single and multi-round surveys for measuring mortality in developing countries", In Vallin, J., Pollard, J., Heligman, L, Methodologies for the collection and analysis of mortality data. International Union for the Scientific Study of Population, Ordina Editions, Liege, Belgium, 1984.

[37] S.G. Trull, "Some Factors Involved in Determining Total Decision Success", Management Science, B-270-B-280, 1996.

[38] E, Turban, J.E, Aronson, and T. Liang, "Decision Support Systems and Intelligent Systems", 574, 2008.

\section{Appendix 1:Application of Decision Support Systems assessment questionnaire}

Dear Respondent

The researcher seeks to carry out a study on the effectiveness of decision support systems in the financial sector and therefore appeals that you respond as honestly so that this study can be as accurate as possible. Information obtained from this study will be used for educational purposes only. All information given will be treated as private and confidential. Please do not write your name, organization or personal details on this questionnaire.

Instructions to the respondent

\begin{tabular}{|c|c|c|c|c|}
\hline Fill in or tick $(\checkmark)$ as appropriate. & D= Disagree (2) & SD=Strongly Disagree (1) \\
\hline $\mathbf{S A}=$ Strongly Agree (5) & $\mathbf{A}=$ Agree (4) & UD=Undecided (3) & D
\end{tabular}

\section{SECTION A: BASIC INFORMATION}

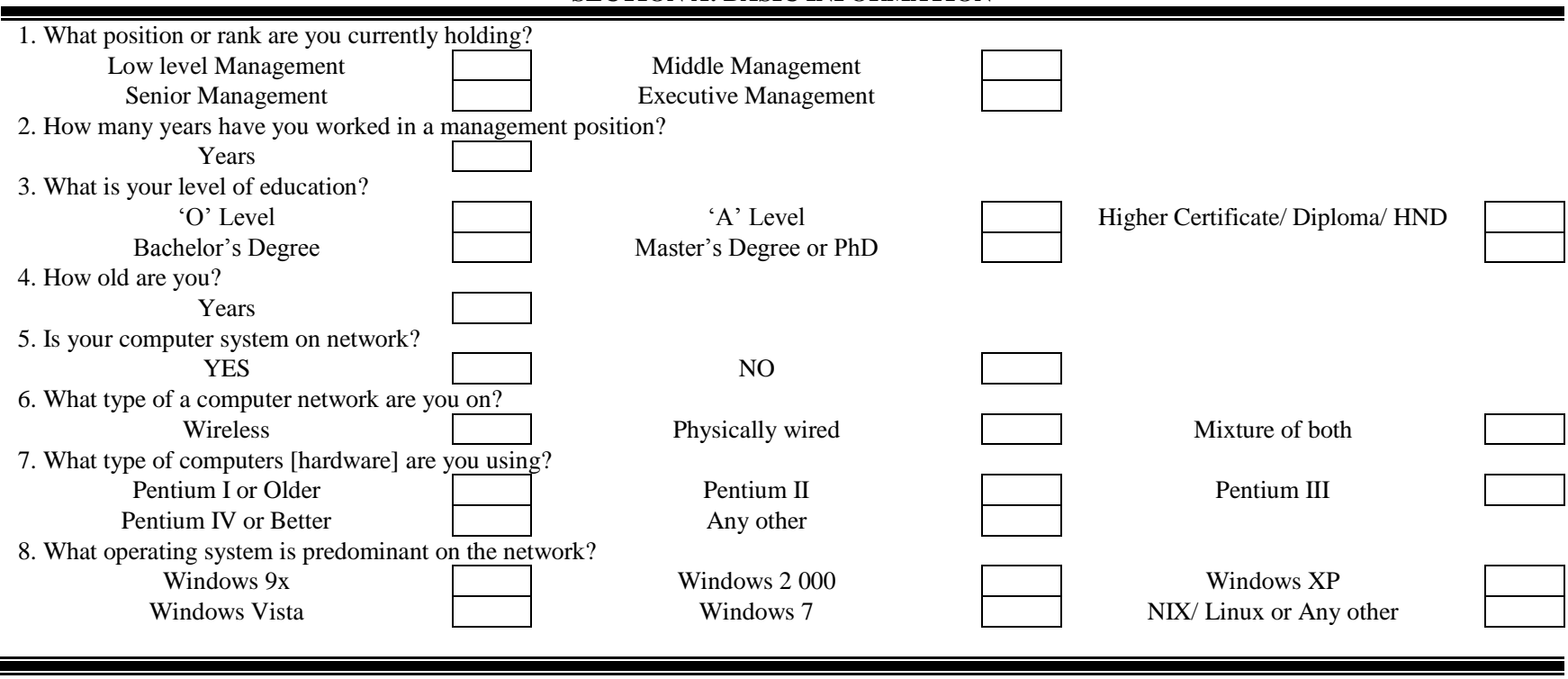

SECTION B

\begin{tabular}{|c|c|c|c|c|c|c|}
\hline \multicolumn{2}{|c|}{ Organizational control } & \multirow[t]{2}{*}{ SA } & \multirow[t]{2}{*}{ A } & \multirow{2}{*}{ UD } & \multirow[t]{2}{*}{ D } & \multirow[t]{2}{*}{ SD } \\
\hline 1 & Computer usage is monitored to measure output performance of employees? & & & & & \\
\hline 2 & System related deadlines are met in completing assignment duties and projects? & & & & & \\
\hline 3 & Information obtained from the system is factual, accurate, consistent and reliable for use? & & & & & \\
\hline 4 & $\begin{array}{l}\text { Output data from the system is readily available for performance monitoring and ad-hoc } \\
\text { querying? }\end{array}$ & & & & & \\
\hline 5 & The system is focused on critical points on which failure cannot be tolerated? & & & & & \\
\hline \multicolumn{2}{|c|}{ Quick Problem solution } & & & & & \\
\hline 6 & $\begin{array}{l}\text { Time taken to arrive at a good decision is greatly reduced by usage of summary output } \\
\text { information obtained from the system? }\end{array}$ & & & & & \\
\hline 7 & $\begin{array}{l}\text { Use of the systems in place increases employee productivity and results in timely information } \\
\text { for decision making? }\end{array}$ & & & & & \\
\hline 8 & $\begin{array}{l}\text { Use of the Decision Support System greatly reduces uncertainty and doubt about alternatives to } \\
\text { allow a reasonable choice? }\end{array}$ & & & & & \\
\hline 9 & The Decision Support System provides substantiated reduced decision cycle time? & & & & & \\
\hline 10 & $\begin{array}{l}\text { Information obtained from the Decision Support System is adequate for making a good } \\
\text { decision? }\end{array}$ & & & & & \\
\hline \multicolumn{2}{|c|}{ Decision making } & & & & & \\
\hline 11 & $\begin{array}{l}\text { The Decision Support System results provide both information and decision making structures } \\
\text { to an individual decision maker and management? }\end{array}$ & & & & & \\
\hline 12 & $\begin{array}{l}\text { Decision Support System aided management is found to make higher quality decisions and } \\
\text { have lower variance in decision quality? }\end{array}$ & & & & & \\
\hline
\end{tabular}




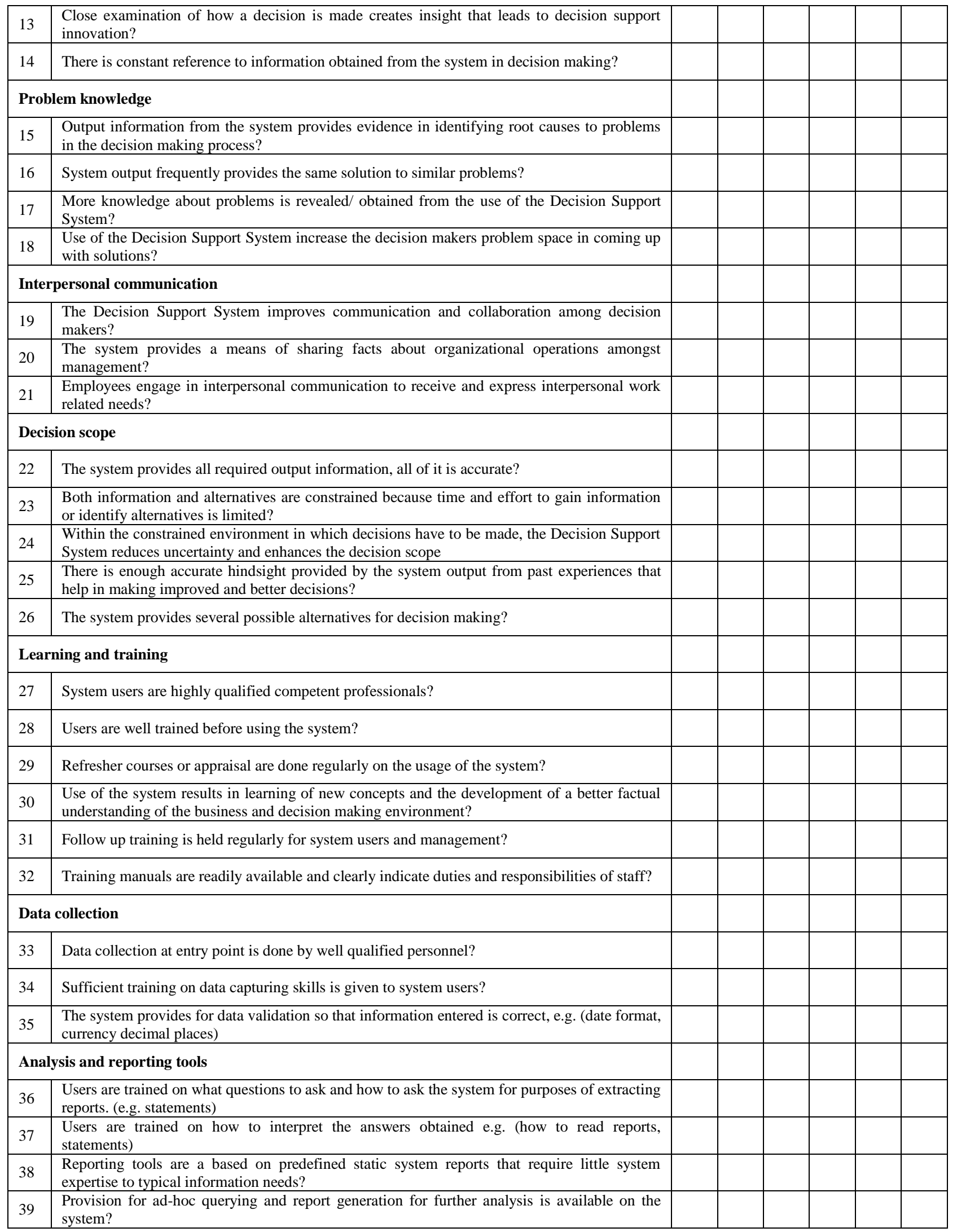

